UCRL-ID-122251

\title{
GAMMA ANALYSIS OF ENVIRONMENTAL SAMPLES FROM THE MARSHALL ISLANDS
}

James L. Brunk

Health and Ecological Assessment Division

September 1995

Work performed under the auspices of the U.S. Department of Energy by Lawrence Livermore National Laboratory under contract W-7405-Eng-48. 


\section{DISCLAIMER}

This report was prepared as an account of work sponsored by an agency of the United States Government. Neither the United States Government nor any agency thereof, nor any of their employees, make any warranty, express or implied, or assumes any legal liability or responsibility for the accuracy, completeness, or usefulness of any information, apparatus, product, or process disclosed, or represents that its use would not infringe privately owned rights. Reference herein to any specific commercial product, process, or service by trade name, trademark, manufacturer, or otherwise does not necessarily constitute or imply its endorsement, recommendation, or favoring by the United States Government or any agency thereof. The views and opinions of authors expressed herein do not necessarily state or reflect those of the United States Government or any agency thereof. 


\section{DISCLAIMER}

Portions of this document may be illegible in electronic image products. Images are produced from the best available original document. 


\section{Table of Contents}

List of Tables.

Abstract.

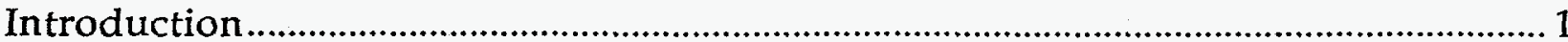

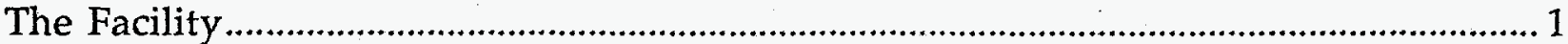

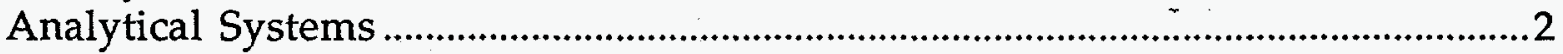

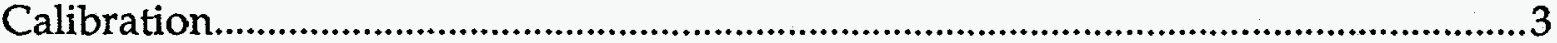

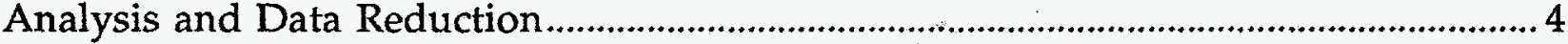

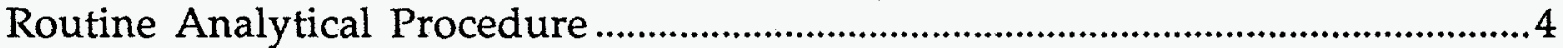

Non - Routine Analytical Procedure .....................................................................5

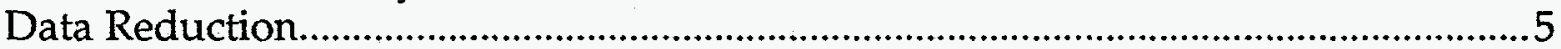

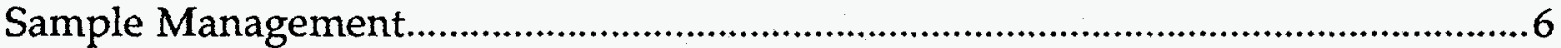

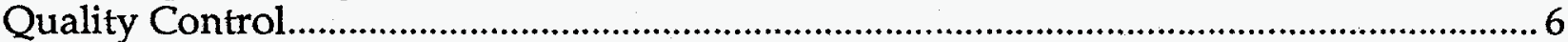

Sample Process Quality Control ...........................................................................6

Analytical Facility Internal Quality Control ....................................................6

Interlaboratory Comparison......................................................................... 7

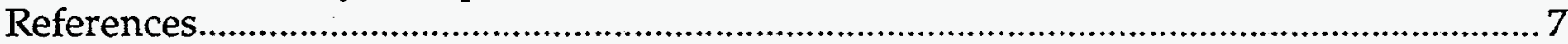

Appendix A - Command Procedures ....................................................................

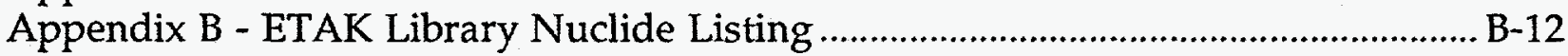

Appendix C - Data Backup Procedure ........................................................................... -19

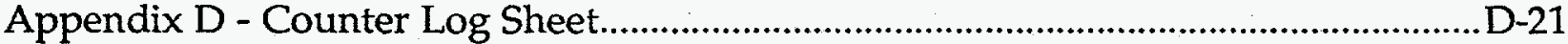

Appendix E - Extract From an Action File..................................................................

\section{List of Tables}

Table 1. Detectors currently in use.

Table 2. Container geometry designations. 


\begin{abstract}
Radiological studies of the fate of nuclear test related debris in the Marshall Islands conducted by members of the Lawrence Livermore National Laboratory generate large number of environmental samples. For more than 20 years, the Low-Level Gamma Spectroscopy Facility has been used to perform the analysis of gamma emitting radionuclides. A brief description of the facility, calibration, counting and analysis procedures is given.
\end{abstract}

\title{
Introduction
}

During 1946 to 1958 the United States conducted 66 nuclear tests in the Northern Marshall Islands. Several of these tests deposited near and intermediate range fallout on islands that have been historically inhabited or have been used for subsistence agriculture. On 1 March 1954, a nuclear weapons test code named BRAVO, was conducted at Bikini Atoll. The explosive yield greatly exceeded expectations resulting in Bikini, Rongelap, Rongerik, Ailinginae, Ailuk, Mejit and Utirik Atolls being contaminated with debris.

For more than 20 years, the Marshall Islands program at Lawrence Livermore National Laboratory (LLNL) has studied the fate of test debris in the tropical atoll environment. This program has been charged with characterizing the extent of the contamination, calculating radiological doses to man through various pathways and investigating remediation techniques. Several sampling trips per year are required to support this scope of work. Approximately 5000 environmental samples, representing constituents of the radiological pathway to man, are collected each year. Most of these samples are assayed for gamma emitting radioisotopes.

\section{The Facility}

The mission of the Low-Level Gamma Spectroscopy Facility (LLGSF) of the Health and Ecological Assessment (HEA) Division of LLNL is to provide the expertise and equipment to perform nondestructive assays of gamma emitting radionuclides contained in a variety of sample matrices. The HEA Division and its predecessors have had facilities since the $1960^{\prime}$ s to determine the concentrations of gamma emitting radionuclides found in the environment (Allen, 1994). These facilities have evolved into the LLGSF.

The facility is housed in Building 379, which was specifically designed and constructed for the purpose of housing the equipment required to perform lowlevel radionuclide activity measurements. This building was constructed in 1983 with carefully chosen low background materials. The floor pad rests on $10 \mathrm{~cm}$ of black serpentine aggregate selected for its low levels of naturally occurring radionuclides. The concrete mixture also contains the same serpentine instead of the local gravel. Special attention was given to the thermal insulation and heating 
and cooling equipment in the counting bay. This reduces the variation in temperature and humidity, contributing to stability in the analytical systems. The electrical service is on emergency generator backup and is filtered and conditioned to lessen power disturbances.

The status of several conditions is monitored on a routine basis. The building power is monitored by a power line disturbance meter. The temperature and humidity are recorded. The detector background is checked weekly.

\section{Analytical Systems}

The current data collection system is the GENIE ${ }^{\circledR}$ system manufactured by Canberra - Nuclear Data ${ }^{1}$. This system is designed for the collection of spectral data from several detectors while simultaneously being able to perform data reduction calculations on a Digital Equipment Corporation ${ }^{2}$ (DEC) VAXStation ${ }^{\circledR}$ running DEC's VMS ${ }^{\circledR}$ operating system. Listed in Table 1 are the detectors currently in use.

Table 1. Detectors currently in use.

\begin{tabular}{ccll}
\hline $\begin{array}{c}\text { System } \\
\text { Number }\end{array}$ & $\begin{array}{c}\text { System } \\
\text { Name }\end{array}$ & \multicolumn{1}{c}{ Detector Manufacturer and Type } & $\begin{array}{c}\text { Size (diameter } \times \\
\text { length) }\end{array}$ \\
\hline 1 & Z094C09 & Canberra HPGe & $51 \mathrm{~mm} \times 46.0 \mathrm{~mm}$ \\
2 & S893A06 & Canberra Ge(Li) & $49.5 \times 42.5$ \\
3 & 6H93A07 & Canberra Ge(Li) & $50.5 \times 50.5$ \\
4 & P794C09 & Canberra HPGe & $48.7 \times 49.5$ \\
5 & 8P93A08 & Ortec Ge(Li) & $43 \times 46$ \\
6 & 5Q93A08 & Canberra Ge(Li) & $49 \times 42$ \\
7 & 7J93A08 & Canberra Ge(Li) & $53 \times 52.5$ \\
8 & DR93A08 & Canberra HPGe & $54.1 \times 55$ \\
9 & 9T93A11 & Canberra HPGe & $46.2 \times 57$ \\
10 & 4F94C08 & Canberra HPGe & $51.3 \times 44$ \\
11 & FE93A11 & Canberra HPGe & $49.8 \times 42.0$ \\
12 & 0P94C08 & Ortec HPGe & $50.4 \times 51.3$ \\
17 & 1B93A12 & Canberra HPGe & $50.5 \times 50$ \\
18 & UL93A12 & Canberra HPGe & $51 \times 45$ \\
19 & II93A12 & Princeton Gamma-Tech HPGe with & \\
20 & & reverse electrode and Be window & $45.42 \times 55$ \\
21 & Y293A20 & Ortec Ge(Li) & $50.4 \times 41.1$ \\
22 & HK93A21 & Canberra Ge(Li) & $49.5 \times 38.5$ \\
23 & L493A21 & Canberra Ge(Li) & $49 \times 47.5$ \\
24 & 2D93A22 & Canberra HPGe & $53 \times 45.5$ \\
\hline
\end{tabular}

1 Canberra Industries Inc., Nuclear Data Systems Division, 150 Spring Lake Dr., Itasca, IL 60143-2096.

2 Digital Equipment Corporation, Maynard, Massachusetts. 
There are currently 20 up looking lithium drifted germanium $(\mathrm{Ge}(\mathrm{Li}))$ and high purity germanium (HPGe) gamma detectors operating. These detectors are contained in steel shields to reduce environmental background radiation. The detectors are connected to high voltage bias supplies and spectroscopy amplifiers. The outputs from the amplifiers are connected to mixer routers that multiplex the signals and allow the use of one analog to digital converter(ADC) per mixer router. The ADC signal goes to the acquisition interface module (AIM) where the pulse height analysis occurs. Each AIM has the capacity to store $2^{31-1}$ counts in each of 63,488 channels. The AIM communicates with the VAX via Ethernet. The Genie software running on the VAX provides for the display and manipulation of the spectral data.

\section{Calibration}

Calibration is the process of identifying and documenting the characteristic parameters of a detector and signal processing system. Our current calculation scheme relies on having the calibration standards as similar as possible in geometry and material composition as the samples of interest. With this system, there are two basic calibrations required for sufficient detector characterization. They are the energy versus channel number relationship that includes a full width at half peak maximum (FWHM) characterization and an efficiency versus energy calibration. Two characterizations that are not performed are the count pile-up correction and the coincidence summing error correction. Pulse pile up occurs when two gamma rays arrive at the detector within the width of the amplifier's output pulse. The low emission rates of the typical environmental level samples (much less than the 1000 $\mathrm{s}^{-1}$ specified in ANSI, 1991) allow us to neglect the error contributions from pulse pile-up. Coincidence summing is radionuclide, geometry and detector dependent. When analyzing samples that emit coincident gamma rays at window to sample distances less than $10 \mathrm{~cm}$, a graph of summing correction versus detector to sample distance is constructed. The factors read from this graph are used to correct the activities (Brunk, 1995). The major isotope of interest, ${ }^{137} \mathrm{Cs}$, does not emit coincident gamma rays.

The energy versus channel number calibration describes the relationship between the channel number and the gamma energy. The calibration software provided with the GENIE system calculates offset, slope and quadratic factors. The FWHM describes the peak shape. This shape varies with peak energy and is a function of the physical construction of the detector and the bias voltage. The detector efficiency describes the relationship between number of gamma rays emitted at a particular energy that deposit all of their energy in the detector and number of the counts detected. The program calculates an efficiency for each of the described gamma rays in the standard and fits a curve to the set of energy - efficiency pairs. This efficiency curve may be described in one of two ways. The software vendor refers to these as empirical, which is calculated via cubic splines, and non-empirical, which is calculated using a least square fit routine. The spline method assumes that with $\mathrm{N}$ calibration energies, $\mathrm{N}-1$ third order polynomials exist such that the first and second 
derivatives are continuous at each of the energies. By definition, the resulting curve passes through each of the energy points. This method is very local in nature causing a maximum extrapolation of $10 \mathrm{keV}$ at the ends of the curve. The least squares fit method does not have this extrapolation restriction. (Canberra, 1989)

\section{Analysis And Data Reduction}

Marshall Islands samples come to the facility in boxes of 72 to 100 samples depending on the sample container. The groups of samples have been separated by experiment or priority and contain blind quality control samples. They are contained in one of three containers. (See Table 2 for the list of the containers used.)

Table 2. Container geometry designations.

Designation Container Material

Dimensions

$\begin{array}{lll}\mathrm{F} & \text { steel } & 8.4 \mathrm{~cm} \text { diameter } \times 4.2 \mathrm{~cm} \text { high } \\ \mathrm{P} & \text { plastic } & 3.7 \mathrm{~cm} \text { diameter } \times 4.4 \mathrm{~cm} \mathrm{high} \\ \mathrm{T} & \text { plastic } & 2.8 \mathrm{~cm} \text { diameter } \times 11.6 \mathrm{~cm} \text { high }\end{array}$

\section{Routine Analytical Procedure}

1. A limited number of samples are received and are stored away from the detector room prior to analysis. By keeping only a small inventory a distance from the detectors the possibility that radiation from the stored samples will raise the background is minimized.

2. Samples are selected for analysis. We prefer to analyze groups of samples that contain similar amounts of activity so that sample throughput can be maximized. The sample name, detector name, sample weight and zero time for each of the samples are entered on the log sheet. Any errors are lined out and initialed.

3. The sample data are keyed or scanned in to the computer and the samples are placed on the detectors. A Digital Command Language (DCL) command procedure, start_bk.com, starts the analyzers. (See Appendix A)

4. Generally, the samples are analyzed for a specific length of time or for a specified counting error for a particular peak. The routine preset count time is for a minimum of 1000 minutes or four percent counting statistic in the ${ }^{137} \mathrm{Cs}$ peak. Samples that are suspected to contain an extremely low level of activity are counted for a longer time. This might be as long as 6000 minutes Lower activity samples might require a longer count time to achieve the required statistical error if the samples are being counted to a specific counting error. (ASTM, 1987. NCRP, 1985) 
5. After the time or statistical error criteria have been met, the analyzers are stopped and the data are transferred to disk storage. The analyzed samples are returned to the experimenter.

\section{Non - Routine Analytical Procedure}

Occasionally, the experimenter will specify special analysis conditions that are different from those used for the routine analysis. The flexibility of the data collection system allows for the rapid change in counting criteria. A common situation is the analysis of $40 \mathrm{~K}$ in vegetation samples. The stopping parameter is to terminate the count after the counting statistic for the $1460 \mathrm{keV}$ gamma ray goes below ten percent. Another common situation is the desire to analyze the sample multiple times for the same stopping criteria. In this case, the sample is simply added to the counting stream as many times as necessary. A third situation occasionally occurs when samples are contained in a non-standard geometry. In this case, the appropriate standard is constructed and a calibration is performed.

\section{Data Reduction}

The spectra are inspected for correct channel - energy relationship and the fit coefficients are adjusted if necessary with the calibration program supplied by Canberra. The DCL command files necessary for analysis are created so that the spectra are conveniently ordered and the file are submitted to the VMS batch processing facility for calculation. A nuclide library containing isotopes that have been found historically in samples from the Pacific Proving Grounds is used to identify the radionuclides in the sample spectra. (See Appendix B) The command procedure new_calc.com causes the nuclides to be identified, activities calculated, weighted means calculated for isotopes having more than one gamma ray and minimum detectable activity limits to be calculated. (See Appendix A) This procedure creates a printout and two disk files containing the activities and the minimum detectable activities in abbreviated form. The results are checked for data entry errors and defects in the measurement process. If the report appears correct, the data are released to the experimenter. If the sample input data are not correct, the incorrect information is replaced with an editing program supplied by Canberra and the spectrum is reanalyzed. If there has been a defect in the spectra due to equipment malfunction, the sample is reanalyzed.

As the VAX's disks become full, the calculated data and spectra are archived. Before the archive process is started, the files produced by the analysis codes are checked for completeness. Results are recalculated for any sample not complete. The analytical result data files are transferred over the Ethernet to a local computer and to the group's central file server. The spectra and the data files are written to magnetic tape and to the LLNL long term archive system. This multi-step archiving process is described in the check list found in Appendix $\mathrm{C}$. 


\section{Sample Management}

The main sample tracking mechanisms use the log sheet that is filled out as the sample count is started and an action file that the termination procedure makes as it executes. The log sheet contains space for the sample identifier, sample description, sample type, sample location, quantity and units, zero time, start date, detector, spectrum identification and the date the data was released to the experimenter. (See Appendix D) The action file created by the count terminating command procedure contains an electronic record of the count parameters. The spectrum identification, detector name, user code, sample identification, start date and time and the count live time are recorded. (See Appendix E)

\section{Quality Control}

Quality Control (QC) is the process undertaken to provide confidence that a process will produce a particular result. The quality control program in use at the facility has two major parts. The first part deals with the accuracy, precision and freedom from contamination of the whole sample process. The second deals with the consistency of the procedures and equipment used for the analysis. Each part is the responsibility of a separate group of individuals.

\section{Sample Process Quality Control}

The experimental program staff take steps to implement the first part, measuring how well the facility analyzes the sample set. Blind duplicates, blanks and external standards are added to the sample sets sent for analysis. This blind method provides a level of checking that thoroughly tests the facility's capabilities. The QC standards contain well-characterized amounts of isotopes chosen for their usefulness in testing channel - energy shifts and efficiency changes. The blanks contain extremely low levels of activity to test the level of contamination of the analytical systems. Usually several isotopes are included in the standard to give a range of gamma ray energies. The activities reflect those of the routine samples. The results of these standard determinations show how accurate the measurements are. The duplicate samples allow the experimenter to compare the precision of several measurements. The blanks show if contamination is present. Tabulated results are provided by the Quality Control Manager to close the information loop.

\section{Analytical Facility Internal Quality Control}

The other part of the QC program is performed at the analytical facility. Special attention is paid to the calibration process making sure that a detector system is not put into service until it performs consistently within the desired precision and accuracy levels. After a system is put into service, weekly measurements designed to detect deviations from these levels are made as part of the routine schedule. The purpose of the procedure is to monitor the performance of the detector systems and make any needed adjustments to the software parameters or electronics to produce 
the correct results for known standards. Background counts are performed once a week to ensure that the detectors and caves are not contaminated by leaky samples.

The computer codes and procedures are documented. Changes made during software development and maintenance are recorded to keep records of the algorithms in use and noting changes in coding or logic. This allows for tracking changes that may affect analytical results.

\section{Interlaboratory Comparison}

Between these two QC efforts, the probability of careless errors in the analysis process becomes less likely. To enhance the confidence level further, world wide intercomparison standards are analyzed. An external organization picks a material with the appropriate level of activity to use in the study. Participating laboratories receive aliquots for analysis. The laboratories analyze the sample and report the activity levels to the study's authors who then tabulate and distribute the results to the participants. Comparison of the data demonstrates the competence of a facility with respect to the other participants. (Kehl, 1995)

\section{References}

Allen, Michael J. (1994), Private communication.

American National Standards Institute (July 2, 1991), American National Standard Calibration and Use of Germanium Spectrometers for the Measurement of GammaRay Emission Rates of Radionuclides, N42.14-1991.

American Society for Testing and Materials, Standard Practices for the Measurement of Radioactivity, D3648-78 (January 27, 1978; Reapproval, October 1987).

Brunk, James L. (September 1995), Instructions for Calibrating Gamma Detectors using the Canberra - Nuclear Data Genie Gamma Spectroscopy System, Lawrence Livermore National Laboratory, Livermore, CA, UCRL-ID-120428.

Canberra Nuclear Products Group (December, 1989), Spectroscopy Applications Algorithms and Software Verification and Validation Manual, 07-0386.

Kehl, Steven R., Mark Mount and William Robison (September 1995), The Northern Marshall Islands Radioecological Survey: A Quality Control Program for Radiochemical and Gamma Spectroscopy, Lawrence Livermore National Laboratory, Livermore, CA, UCRL-ID-120429.

National Council on Radiation Protection and Measurements (February 1, 1985), A Handbook of Radioactivity Measurements Procedures, NCRP Report No. 58. 
Appendix A - Command Procedures 


\section{START BK.COM}

\$! START_BK.COM - a command procedure to start detectors for Bikini type samples lones that have the sample name type of f9110spr42f000)

\$! By Jim Brunk

$\$$ : Started 18 Feb 1993

$\$$ Last Edit 17 Aug 1994

$\$$

$\$ !$

$\$ !$

!

17 Aug 1994 added preset live time

detector count $=1$

max detector $=0$

$\$$ start_count $=0$

detector_loop:

online $=$ online "detector count'

detector = detector 'detector count'

if online

then

inquire answer "start detector "E\$extract $(0,2$, detector)" ?"

The number of the detector to be acted on

! The maximum number of detectors to be started

! Initialize the start count

o letters of the detector

if answer eqs. "" then goto end ! <CR> means end...

if answer

then

max detector $=\max$ detector+1 $\quad$ Increment the maximun number

start count $=\operatorname{star} \bar{t}$ count +1 increment the start count

start-start count" " "detector" I If online put detector name in the list endif

endif

detector_count=detector_count +1 Increment the number of detector

if detector_count eq. 16 then detector_count=detector_count+1 i There is no Detector 16

if detector count.gt. 24 then goto endlist Exit the Loop

goto detector_loop

Sendlist:

detector $=0$

Initialize the detector number

outloop:

detector $=$ detector +1

if detector . gt. max detector then goto bye

start=start 'detector.

write sys\$output "I

write sys\$output " "start' [Number "detector" of "max detector' detectors.]"

call startit istart.

goto out loop

\$bye:

Sexit

\$startit: subroutine

$\$ 1$ Command procedure to start spectra

$\$$ ! by Jim Brunk

\$! started 20 March 1992

$\$$ ! last edit - 16 April 1993

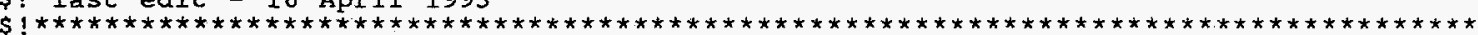

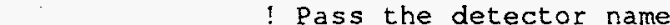

if fSextract $(3,2$, sample name) eqs. "01" then mon ="jan"

if f\$extract $(3,2$, sample name) eqs. "02" then mon " "feb"

if fSextract (3,2, sample name) eqs. "03" then mon ="mar"

if f sextract (3,2, sample name) .eqs. "04" then mon "apr"

if f\$extract (3,2, sample name) .eqs. "05" then mon = "may"

if $f$ Sextract $(3,2$, sample name) .eqs. "06" then mon = "jun"

if f\$extract $(3,2$, sample name) eqs. "07" then mon = "jul"

if f Sextract (3,2, sample name) .eqs. "08" then mon "aug"

if $f$ sextract $(3,2$, sample name) eqs. "09" then mon $=$ "sep"

if f $\$$ extract $(3,2$, sample name) eqs. "10" then mon = "oct"

if f\$extract (3,2, sample name) .eqs. "11" then mon = "nov"

if $f$ sextract $(3,2$, sample name) .eqs." 12 " then mon $=$ "dec"

year $=$ f $\$$ extract $(1,2$, sample name $)$

tzero = "1-"mon"-'ifsstring (year)"

write sys\$output "The sample type is: "type"

: show the sample type 


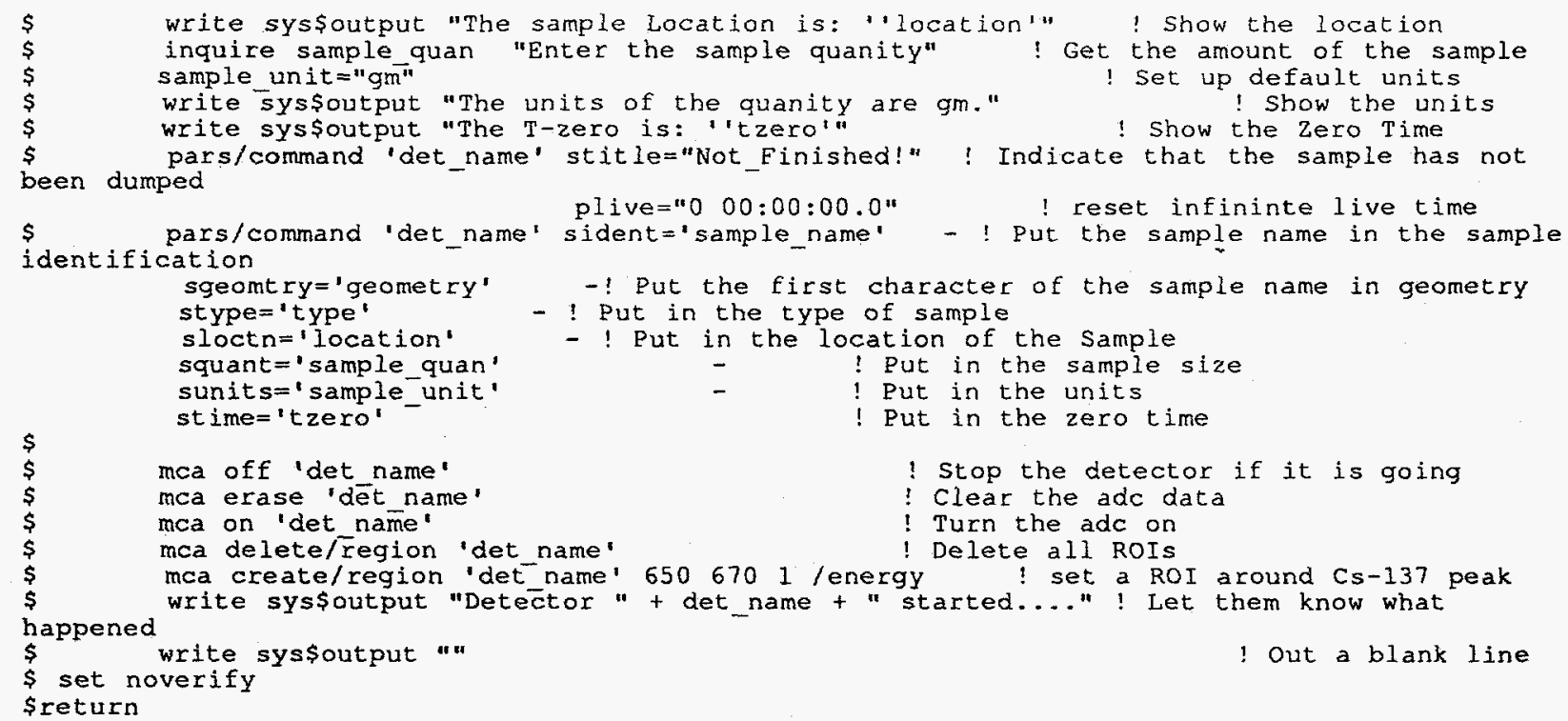




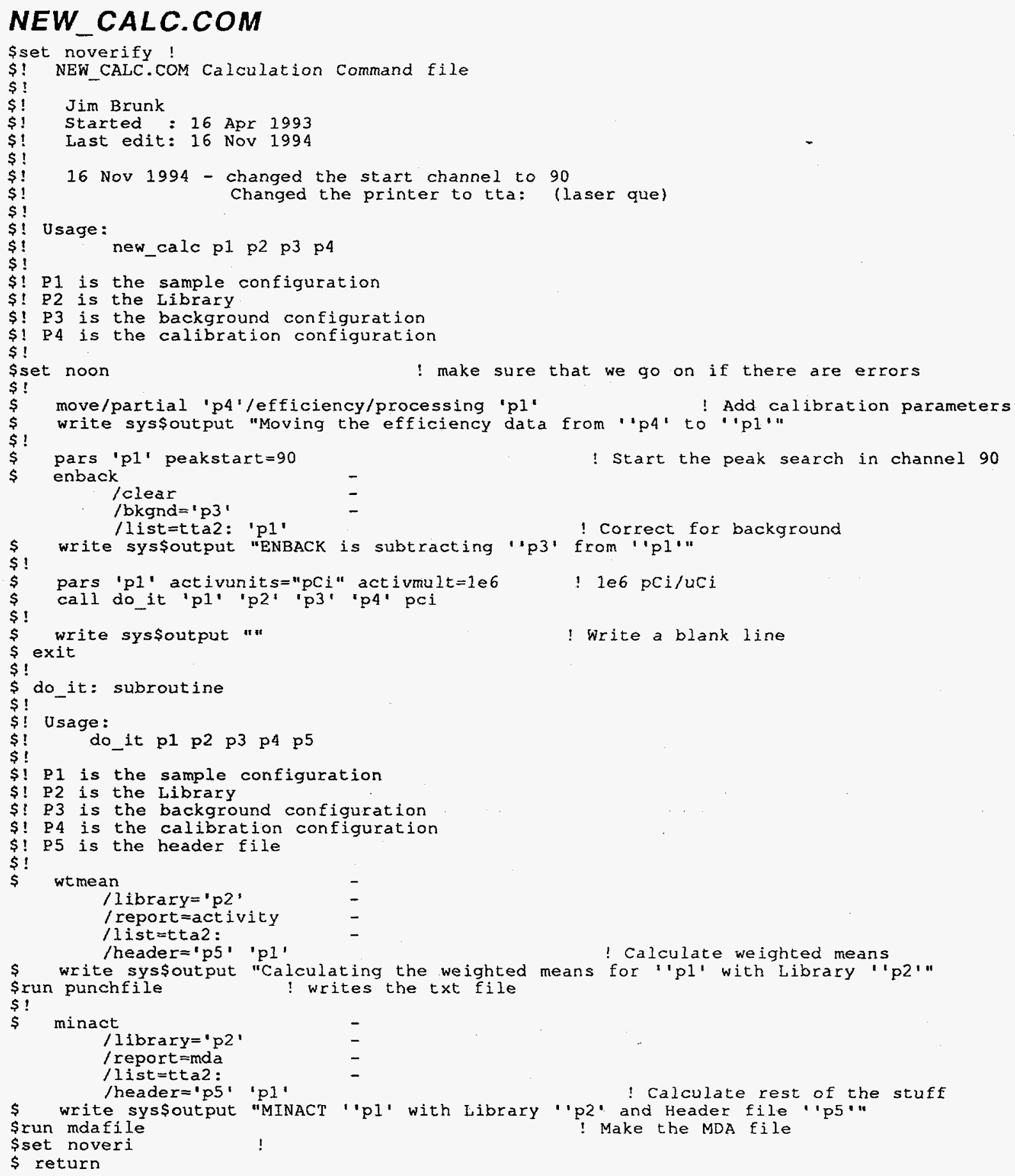


Appendix B - ETAK Library Nuclide Listing 


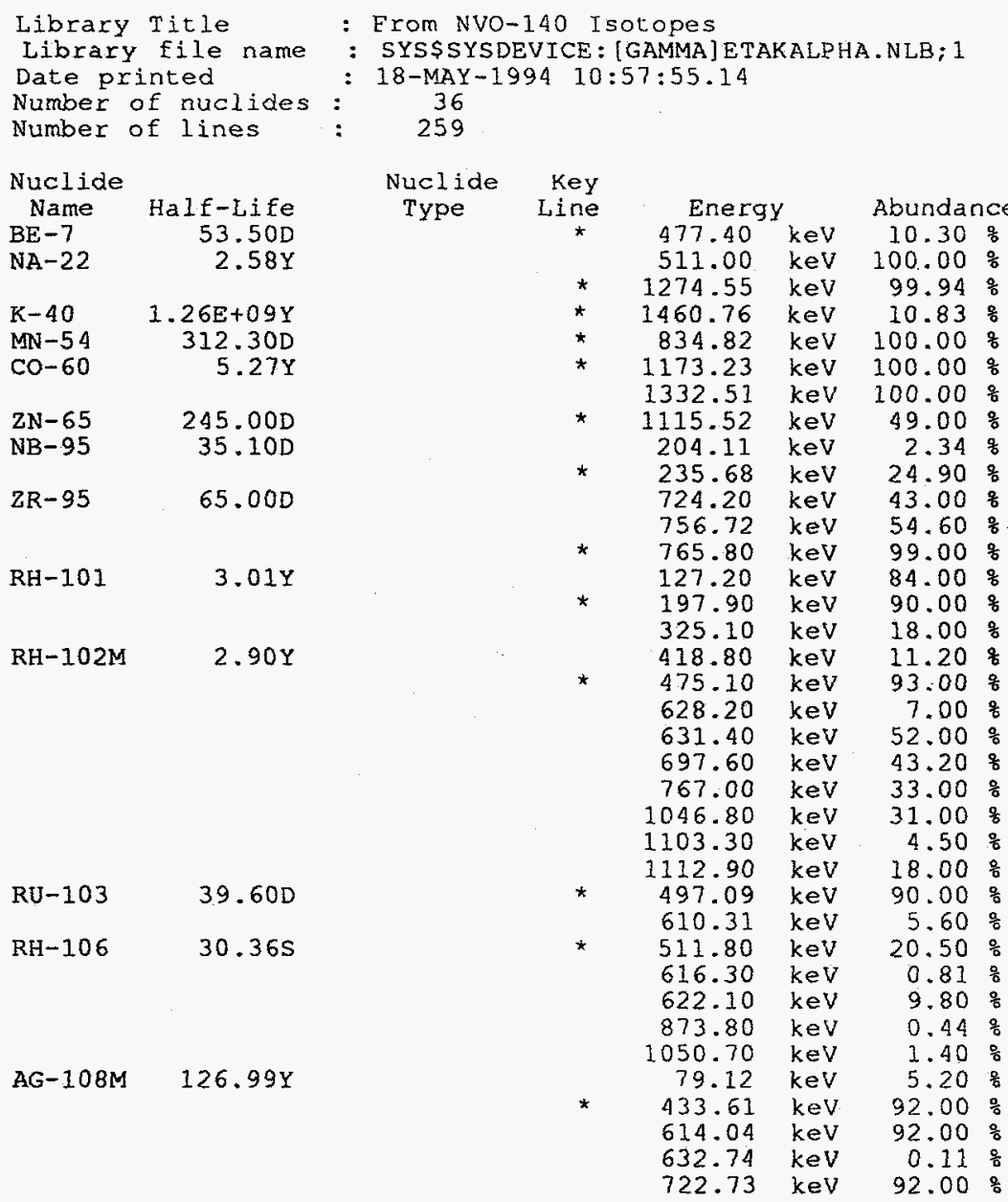




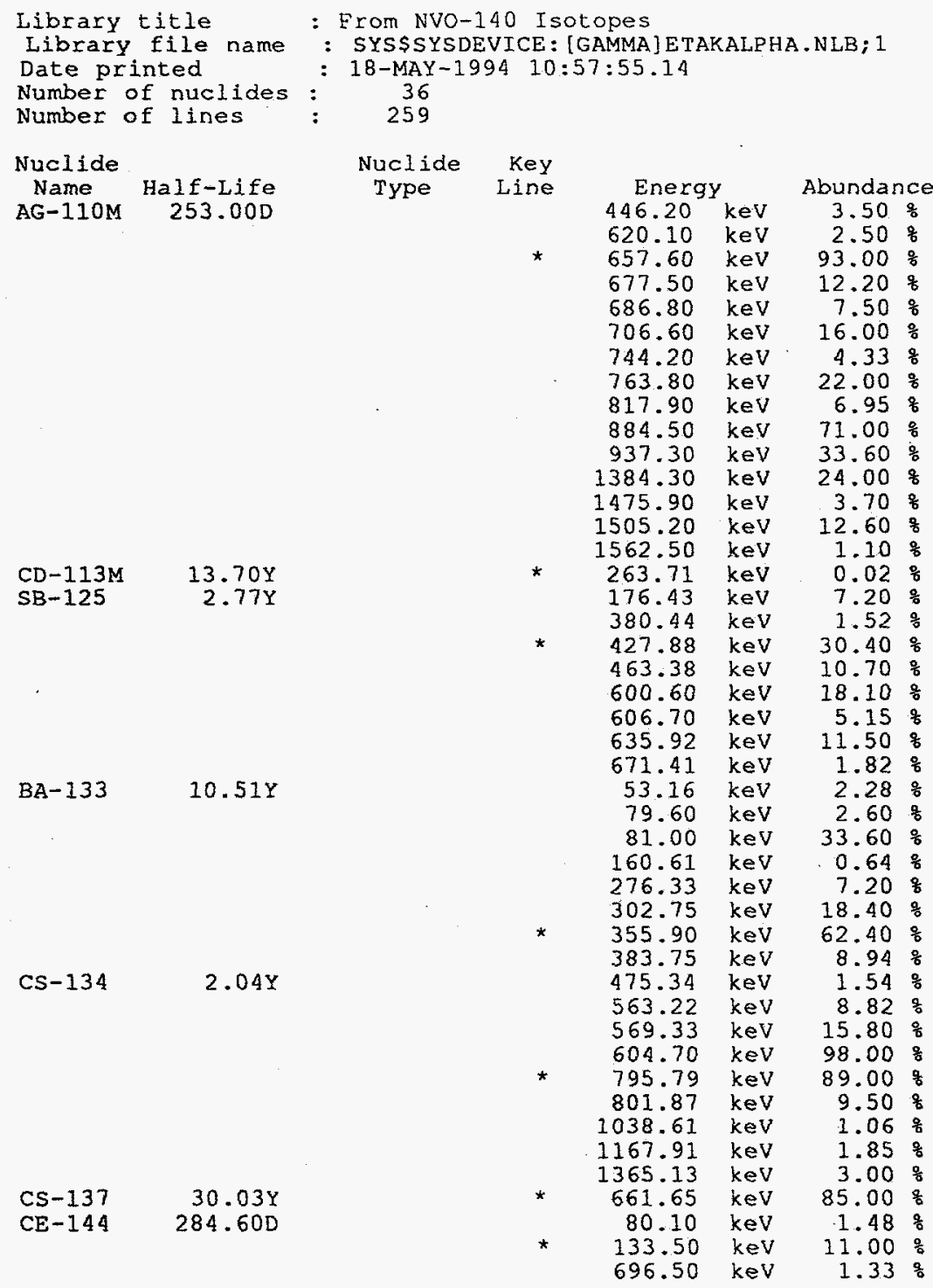

R-14 


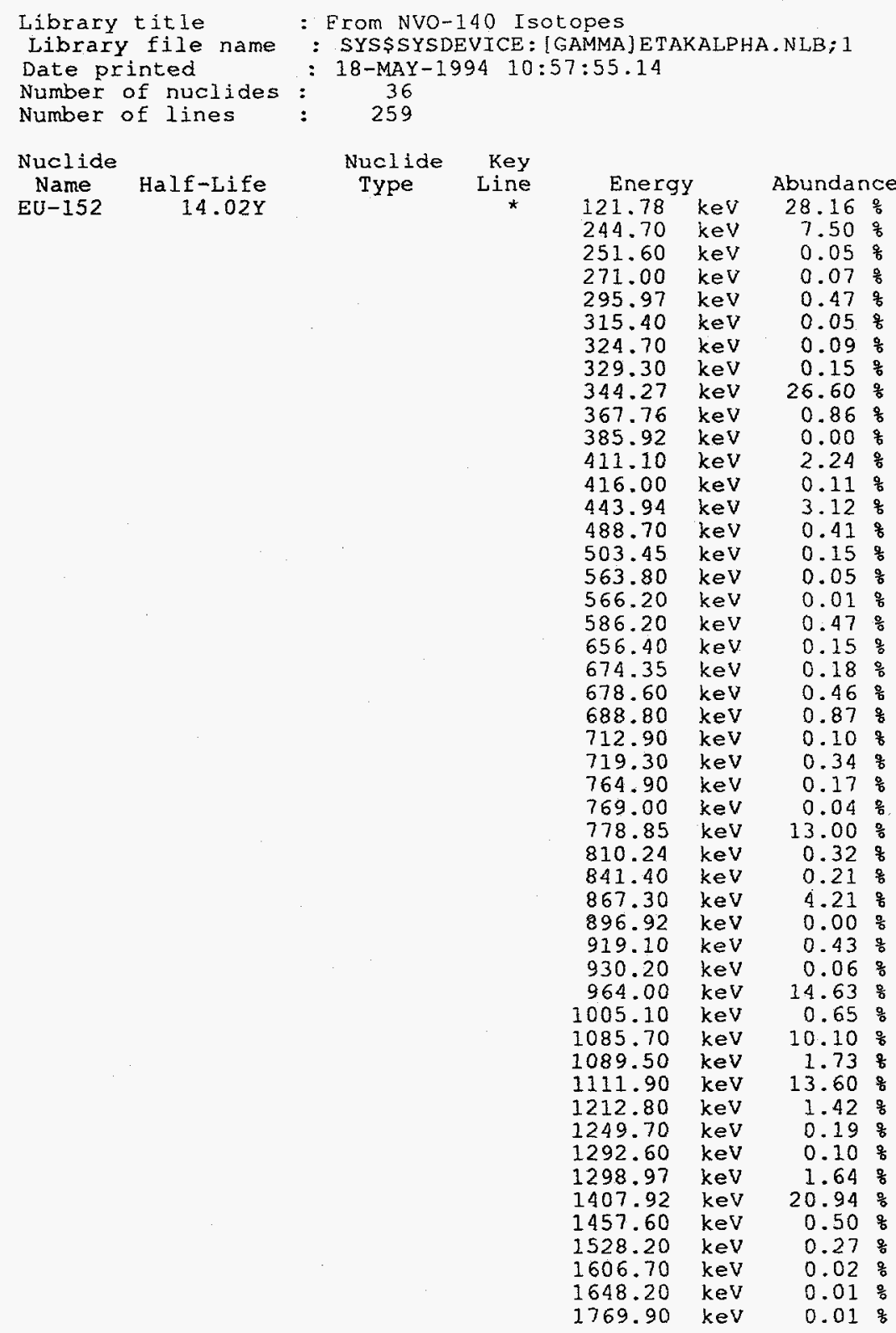




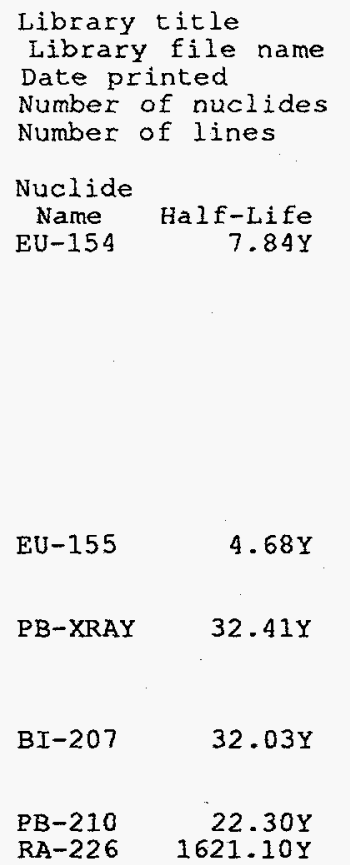

$\begin{array}{cc}\text { Nuclide } & \text { Key } \\ \text { Type } & \text { Line }\end{array}$

$\star$
Energy $123.14 \mathrm{keV}$ $248.04 \mathrm{keV}$
$591.74 \mathrm{keV}$ $692.41 \mathrm{keV}$

$723.30 \mathrm{keV}$

$756.87 \mathrm{keV}$

$873.19 \mathrm{keV}$

$996.32 \mathrm{keV}$

$1004.76 \mathrm{keV}$

$1274.39 \mathrm{keV}$

$1596.48 \mathrm{keV}$

$60.01 \mathrm{keV}$

$86.55 \mathrm{kev}$

$105.32 \mathrm{keV}$

$72.80 \mathrm{kev}$

$74.97 \mathrm{keV}$

$84.80 \mathrm{keV}$

$87.30 \mathrm{keV}$

569.62

1063.65

1770.18

46.50

186.14

241.96

295.20

351.92

609.27

665.40

742.48

768.35

785.80

806.16

934.06

1120.28

1155.17

1238.13

1280.98

1377.64

1401.44

1407.98

1509.22

1661.24

1729.55

1764.49

1838.33

1847.44

2118.52

2204.14

2447.63
Abundance

$40.50 \%$

$6.59 \%$

4.84 \%

$1.70 \%$

19.70 \%

4.34 \%

$11.50 \%$

$10.30 \%$

$17.30 \%$

33.508

$1.67 \%$

1.32 웅

32.20 용

22.80 \%

$59.88 \%$

$100.00 \%$

$34.89 \%$

10.968

$98.00 \%$

$77.00 \%$

6.82 음

4.108

$4.00 \%$

$7.90 \%$

20.20 영

40.10 음

$48.40 \%$

$1.65 \frac{\circ}{2}$

$0.00 \%$

$5.32 \%$

$1.21 \%$

1.31 움

$3.34 \%$

$16.00 \%$

1.82 各

$6.20 \%$

$1.56 \%$

$4.18 \%$

1.448

$2.60 \%$

$2.30 \%$

$1.21 \%$

$3.07 \%$

16.60 \%

$0.41 \%$

$2.20 \%$

1.23 \&

$5.30 \%$

$1.65 \%$ 


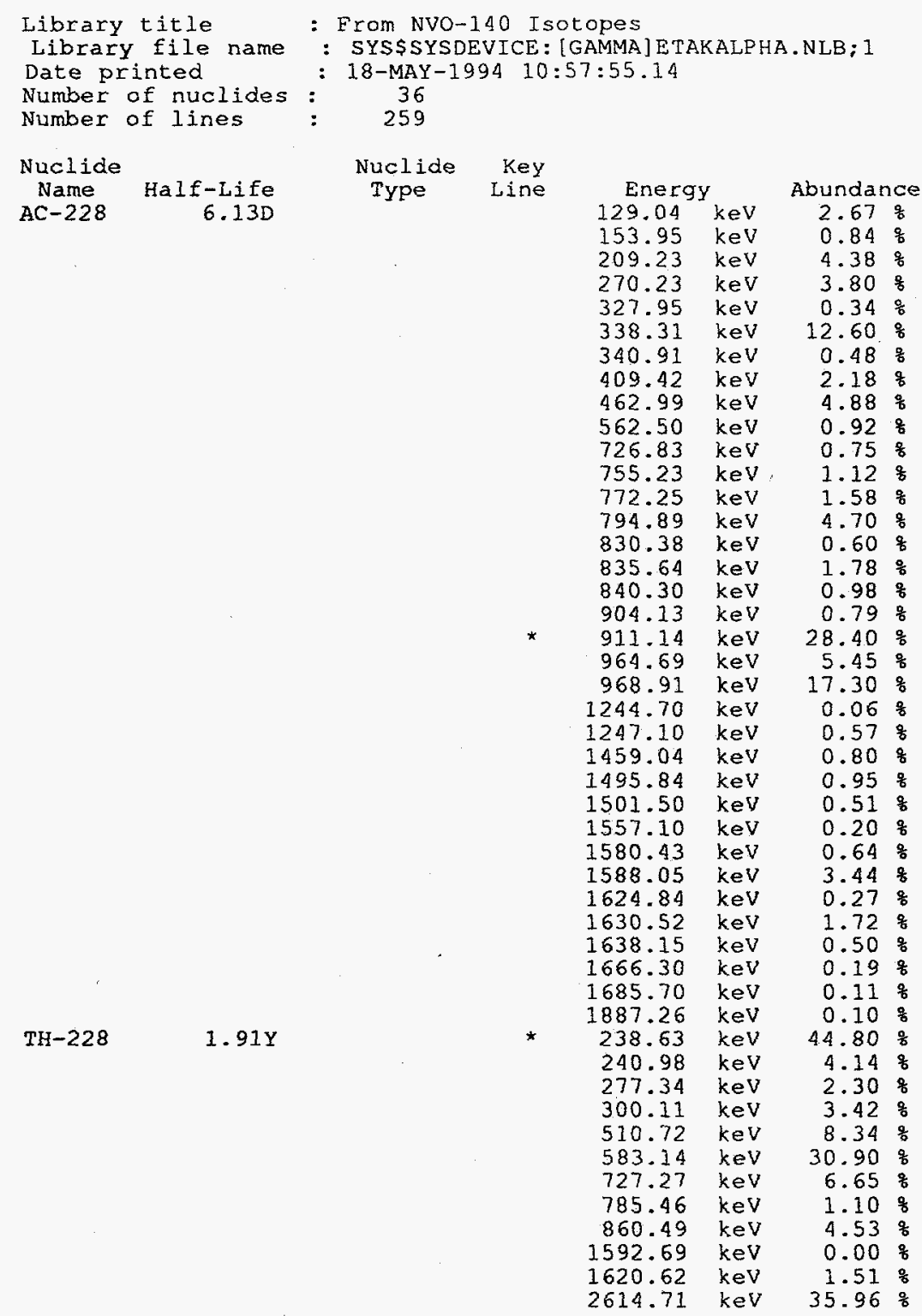
Date printed 18-MAY-1994 10:57:55.14 


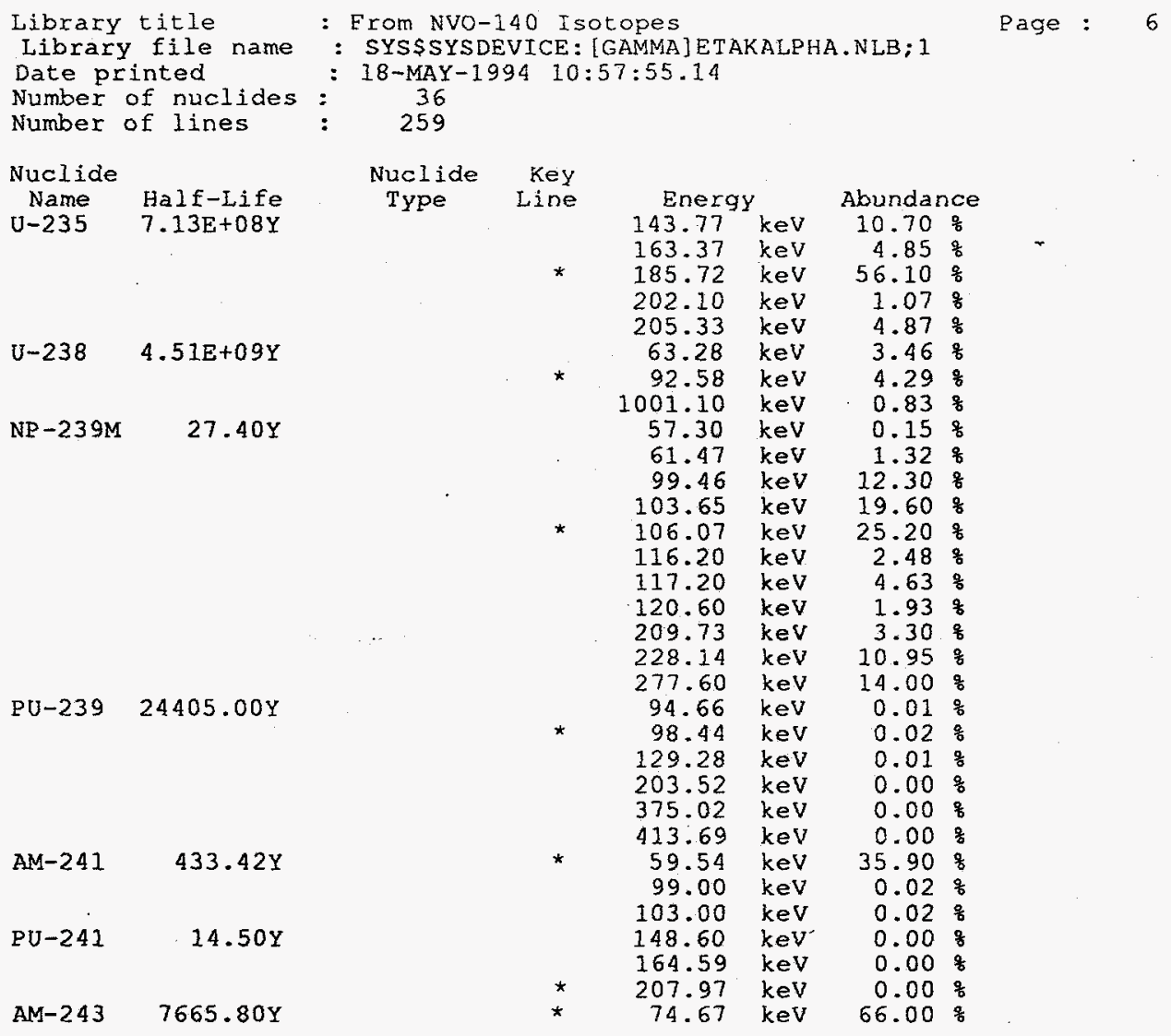

\section{Reference}

United States Atomic Energy Commission (October 1973), Walter E. Nervik and Roger Ray, editors, Enewetak Radiological Survey, NVO-140, Vol. 1. 
Appendix C - Data Backup Procedure 
VAX Gamma Data Archive Check List

Note: The $\$$ is the VAX prompt (which may not be a $\$$ at all, it may be something like EVNLLG $>$...) and is not to be entered. The $>$ and FTP> are prompts for the PC and are not to be entered. Commands to the computers are written in italics. The user is assumed to know how to, use the appropriate VAX DCL, FTP, dBase and Novell procedures.

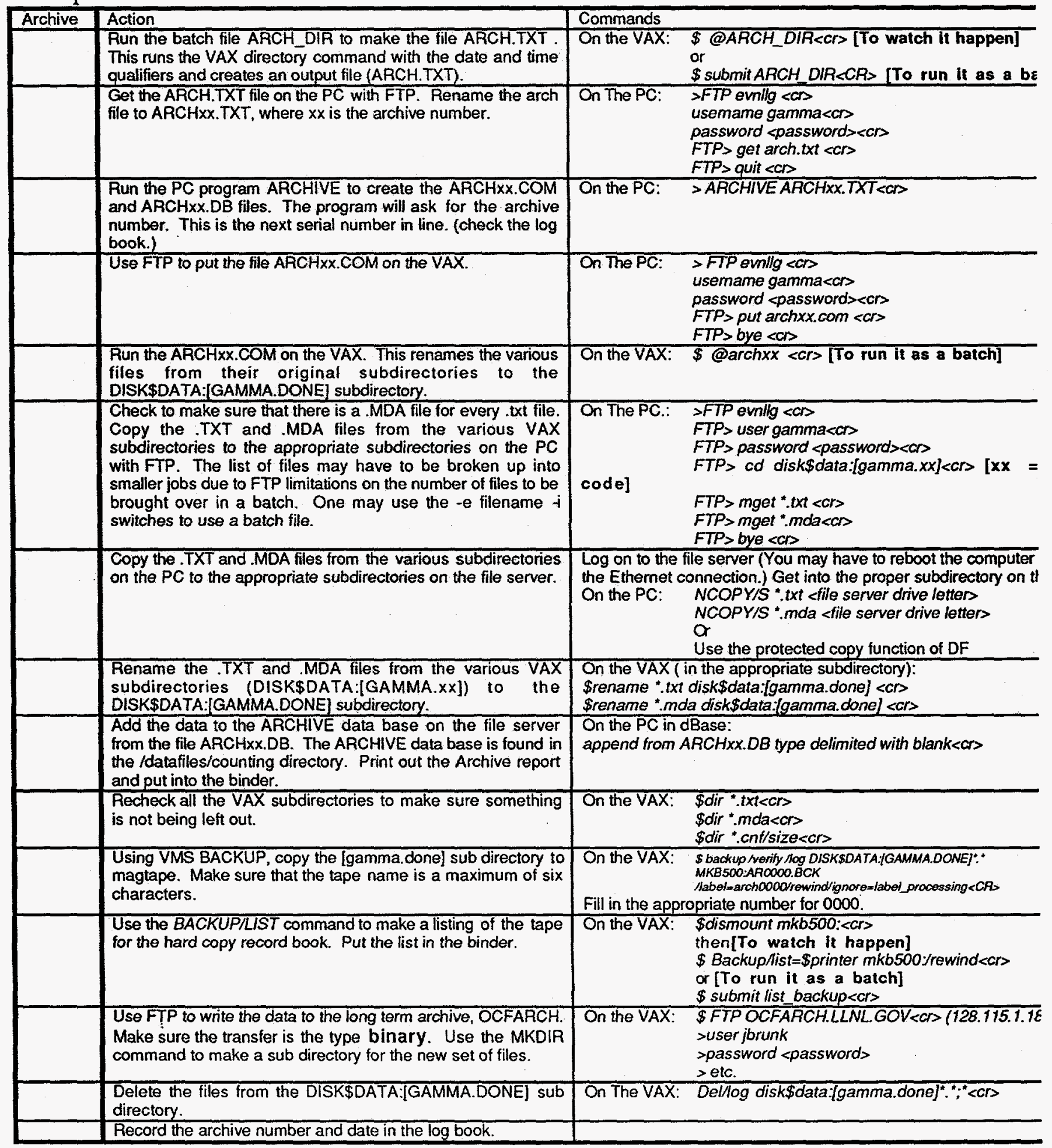


Appendix D - Counter Log Sheet 


\section{B379 Genie Sample Log Sheet}

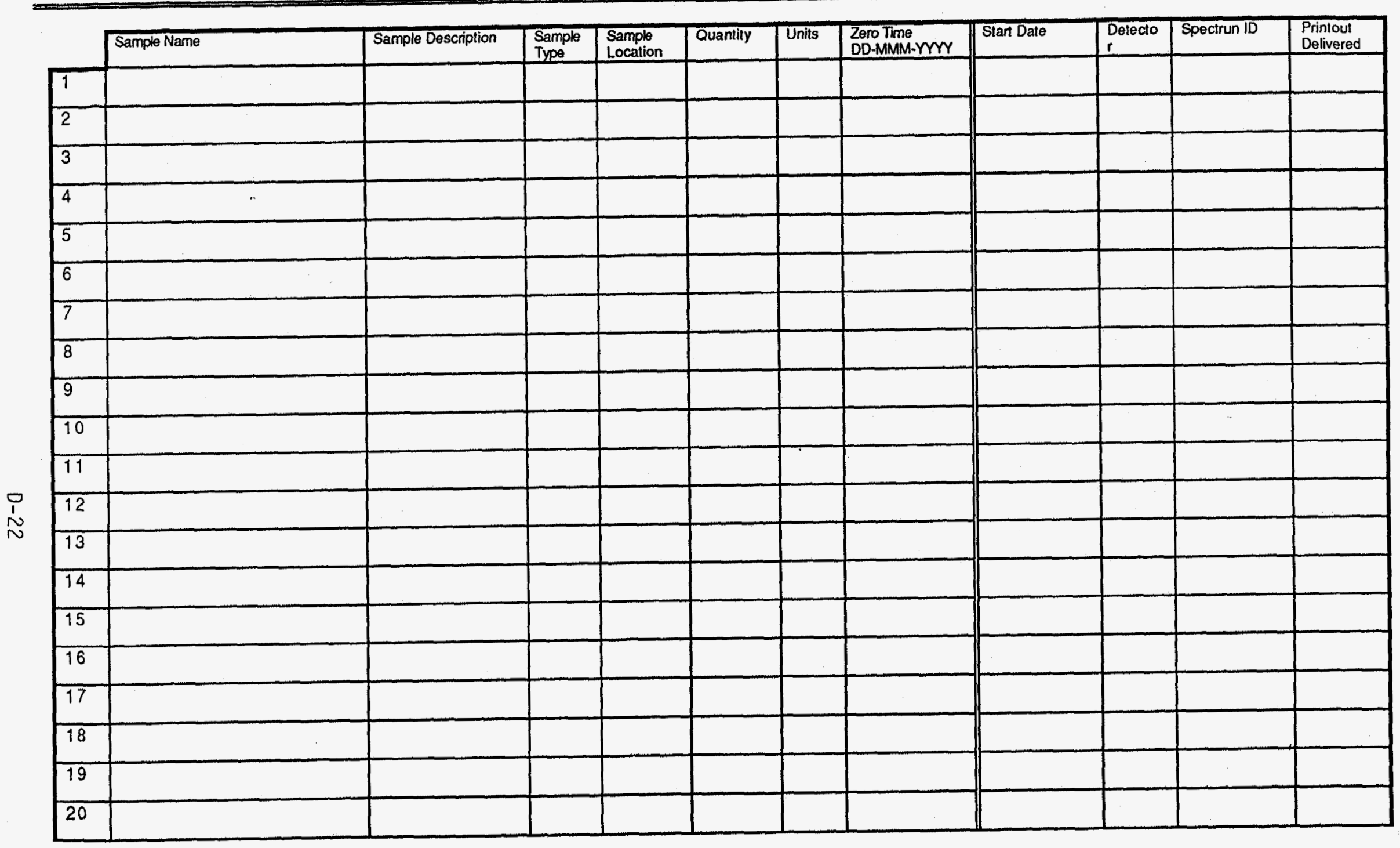

Submitted by: 
Appendix E - Extract From an Action File 
The action file is a record generated at the time a sample count is terminated. The essential counting particulars are recorded. The spectrum identification, detector name, sample name, count start date and time, and count live time.

\section{Extract}

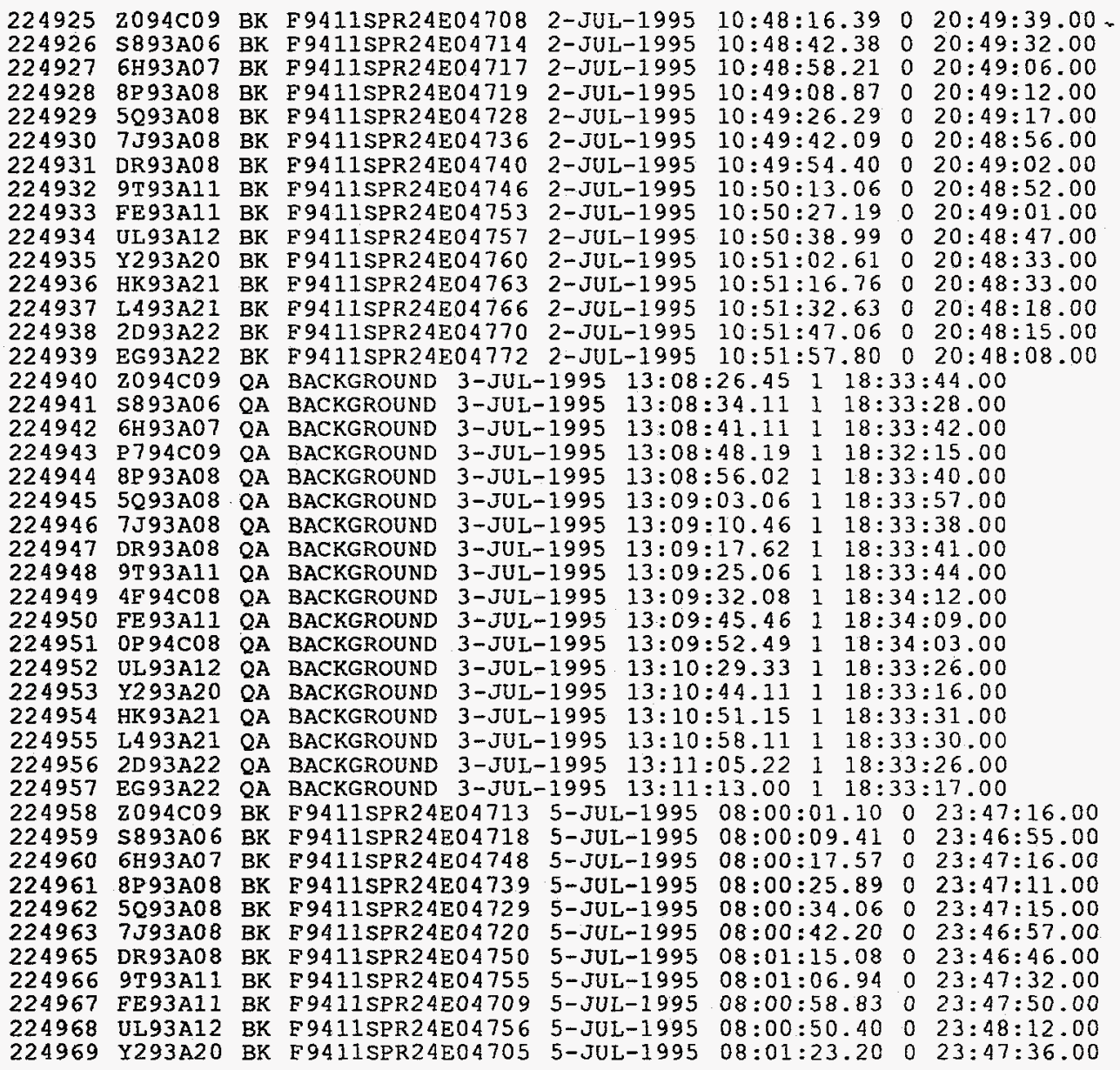

